\title{
Theoretical Performance Evaluation of a Marine Solid Propellant Water-Breathing Ramjet Propulsor
}

\author{
Nachum E. Eisen * and Alon Gany \\ Faculty of Aerospace Engineering, Technion-Israel institute of Technology, Haifa 3200003, Israel; \\ gany@tx.technion.ac.il \\ * Correspondence: nachum.eisen@gmail.com
}

Received: 24 November 2019; Accepted: 18 December 2019; Published: 20 December 2019

\begin{abstract}
This work analyzes and presents theoretical performance of a marine water-breathing ramjet propulsor. A conceptual scheme of the motor is shown, the equation of thrust is presented, and the dependence on cruise velocity and depth are discussed. Different propellant compositions, representing a wide variety of formulations suitable for propelling a water-breathing ramjet, are investigated. The theoretical results reveal that the specific impulse of a water-breathing ramjet can increase by as much as 30\% compared to a standard rocket, when using a conventional hydroxyl terminated polybutadiene (HTPB)-ammonium perchlorate (AP) propellant, which does not react chemically with the water. When employing a water-reactive propellant containing metal particles such as magnesium or aluminum, the specific impulse may be more than doubled. The thrust coefficient of the propulsor was computed at different cruise velocities and depths and was found to be greater than the predictable drag even at significant depth.
\end{abstract}

Keywords: underwater propulsion; water-breathing ramjet; marine ramjet; water ducted rocket

\section{Introduction}

The search for underwater high-speed cruising reveals certain high-thrust marine propulsion concepts which are parallel in principle to their aeronautical counterparts [1]. Rocket engines can propel high-speed underwater vehicles just like aeronautical vehicles. Independent of speed and ambience medium, rocket engines provide very high thrust and do not need air for their operation, hence, they can suite underwater vehicles. However, their specific fuel (propellant) consumption is very high and, thus, they enable only a limited range. Therefore, propulsion principles utilizing the surrounding water as a working fluid as well as a chemical reactant (usually oxidizer), have been considered [2-8]. One of the interesting concepts for propelling high-speed underwater vehicles is the solid propellant water-breathing ramjet [4-8]. It is a powerful propulsion means, independent of atmospheric air, hence, it can operate fully and deeply underwater.

The basic principle of the marine water-breathing ramjet is to utilize the high dynamic (ram) pressure, resulting from the high-speed motion, in order to ingest water into the combustion chamber of the motor, thus increasing the thrust and energetic performance of the propulsor. This work focuses on theoretical prediction of the performance of a water-breathing underwater solid propellant ramjet motor.

The design of an underwater solid propellant water-breathing ramjet is similar to the design of an aeronautical ducted rocket. Water enters the motor through an inlet located in the front of the vehicle and is sprayed through a porous wall into the combustion chamber. Due to the high temperature in the combustion chamber, the incoming water boils and then mixes with the combustion products, forming a high-speed exhaust jet that provides the thrust necessary to propel the vehicle. A conceptual illustration of a solid propellant water-breathing ramjet is presented in Figure 1. 


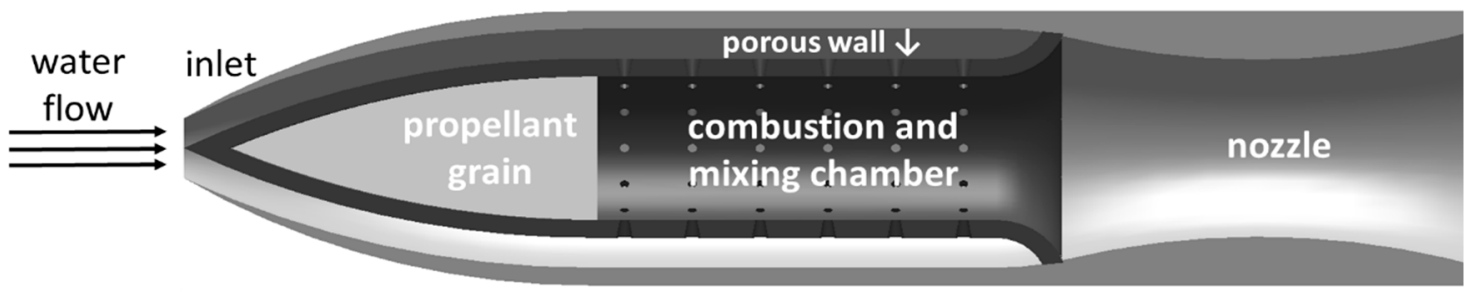

Figure 1. Conceptual illustration of a marine solid propellant water-breathing ramjet.

Similarly to solid rocket motors (SRMs), the solid propellant grain can provide high thrust without the addition of water, as well. Nevertheless, the mere addition of water, entering through an inlet due to the vehicle motion, and its further conversion into steam because of the high heat release of the burning solid propellant, increases the thrust and the specific impulse, even with no chemical interaction. Greater performance improvement can be obtained when employing water-reactive propellant compositions, which utilize the incoming water as an oxidizer to increase heat release in addition to using it as a source for steam which increases the mass flow rate of the exhaust jet. Certain metals are known to react very exothermically with water and may be considered for inclusion as water reactive ingredients in propellants. Typically, the reaction of metals with water generates hydrogen besides metal oxides. Table 1 presents theoretical physical and thermochemical properties of selected metals. While the gravimetric heat of reaction is related to the mass of fuel (propellant) carried on board, the volumetric heat of reaction reflects the energy per unit volume and is mainly significant in volume-limited systems.

Table 1. Maximum theoretical gravimetric and volumetric heat of reaction and hydrogen generation for selected metals with liquid water, listed in the order of their volumetric heat of reaction (data adapted from [9]).

\begin{tabular}{cccccc}
\hline Fuel & $\begin{array}{c}\text { Density } \\
{\left[\mathrm{g} / \mathrm{cm}^{3}\right]}\end{array}$ & $\begin{array}{c}\text { Gravimetric Heat of } \\
\text { Reaction } \\
{[\mathrm{kJ} / \mathrm{g}]}\end{array}$ & $\begin{array}{c}\text { Volumetric Heat of } \\
\text { Reaction } \\
{\left[\mathrm{kJ} / \mathrm{cm}^{3}\right]}\end{array}$ & $\begin{array}{c}\text { Specific } \mathrm{H}_{2} \text { Mole } \\
\text { Production }[\mathrm{mol} / \mathrm{g}]\end{array}$ & $\begin{array}{c}\text { Specific Volumetric } \mathrm{H}_{2} \\
\text { Mole Production } \\
{\left[\mathrm{mol}_{\mathbf{c m}} \mathrm{cm}^{3}\right]}\end{array}$ \\
\hline $\mathrm{Be}$ & 1.85 & 36.1 & 66.7 & 0.111 & 0.21 \\
\hline $\mathrm{B}$ & 2.35 & 18.4 & 43.2 & 0.139 & 0.34 \\
\hline $\mathrm{Al}$ & 2.70 & 15.2 & 40.9 & 0.055 & 0.15 \\
\hline $\mathrm{Zr}$ & 6.49 & 5.7 & 37.2 & 0.022 & 0.14 \\
\hline $\mathrm{Mg}$ & 1.74 & 13.0 & 22.6 & 0.041 & 0.072 \\
\hline $\mathrm{Li}$ & 0.54 & 25.5 & 13.8 & 0.072 & 0.039 \\
\hline $\mathrm{Na}$ & 0.97 & 2.8 & 2.7 & 0.022 & 0.021 \\
\hline
\end{tabular}

It is apparent from Table 1 that beryllium reacts extremely exothermically with water both in terms of weight and volume, yet, beryllium and its products are notoriously toxic and therefore are ruled out. Second to beryllium is boron, which demonstrates a promising theoretical heat and gas (i.e., hydrogen) release. In practice, it is hard to obtain high combustion efficiency of boron (though Rosenband et al. [10] have demonstrated combustion of boron in steam), and in addition boron is a relatively expensive ingredient. Hence, for practical applications, aluminum is commonly considered. Aluminum reacts with water to form aluminum oxide (alumina) or aluminum hydroxide, and hydrogen, while releasing a significant amount of heat, as presented in Equation (2). However, aluminum does not combust readily as a thin layer of aluminum oxide naturally forms on the exposed surfaces of the aluminum particles and passivates the metal substrate to inhibit oxidation progression. Different approaches for overcoming the alumina coating problem are discussed extensively in the literature [11-14]. Zirconium has high volumetric heat of reaction, yet lower than that of aluminum. In addition, its other energetic parameter, gravimetric heat of reaction, is substantially inferior to that of 
more regularly used metals such as aluminum and magnesium. Relatively to aluminum, magnesium has a lower energy density, but the magnesium-water reaction is easier to initiate. Therefore, some researchers suggested using magnesium $[4,5,7,8]$ or using an aluminum-magnesium mixture [6]. The high-temperature stoichiometric reactions of boron, aluminum, and magnesium with water are presented here:

$$
\begin{aligned}
2 \mathrm{~B}+3 \mathrm{H}_{2} \mathrm{O} & \rightarrow \mathrm{B}_{2} \mathrm{O}_{3}+3 \mathrm{H}_{2}+397 \frac{\mathrm{kJ}}{\mathrm{mol}^{\prime}} \\
2 \mathrm{Al}+3 \mathrm{H}_{2} \mathrm{O} & \rightarrow \mathrm{Al}_{2} \mathrm{O}_{3}+3 \mathrm{H}_{2}+818 \frac{\mathrm{kJ}}{\mathrm{mol}^{\prime}} \\
\mathrm{Mg}+\mathrm{H}_{2} \mathrm{O} & \rightarrow \mathrm{MgO}+\mathrm{H}_{2}+312 \frac{\mathrm{kJ}}{\mathrm{mol}} .
\end{aligned}
$$

One may note that lithium has a very high gravimetric heat of reaction in addition of its high reactivity with water. However, besides the difficulty in handling lithium, it has been considered for application only as a liquid fuel in its molten phase and not as solid fuel [15].

The chamber pressure in the marine water-breathing ramjet is dictated by the cruise speed, and its maximum value at a given speed is equal to the stagnation pressure of the incoming water flow:

$$
P_{0}=P_{a}+\frac{1}{2} \rho_{w} u^{2},
$$

where, $P_{0}=$ stagnation pressure; $P_{a}=$ ambient pressure; $\rho_{w}=$ water density; $u=$ cruise velocity.

The stagnation pressure increases with the cruise speed (as shown in Figure 2); the increased chamber pressure at higher velocities enable enhanced conversion of thermal energy to kinetic energy in the exhaust nozzle, increasing the energetic performance of the motor.

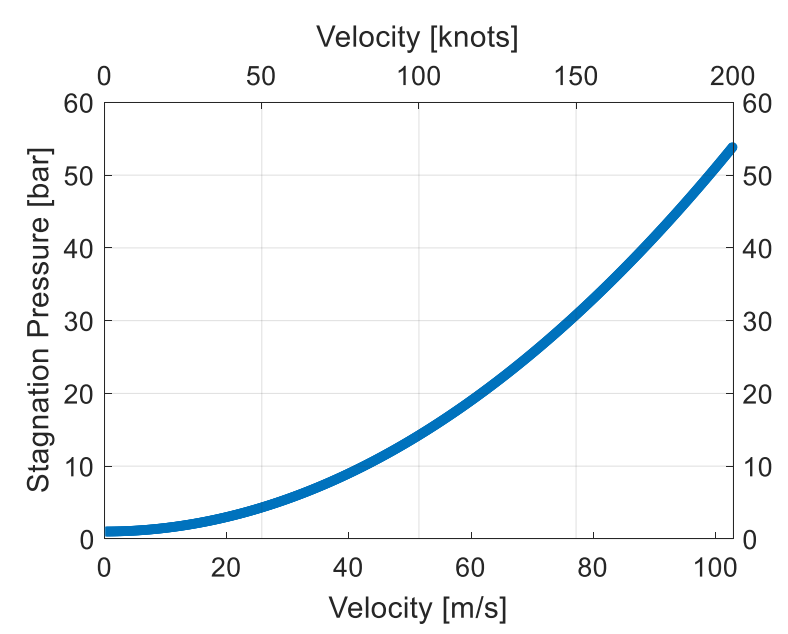

Figure 2. Stagnation pressure vs. cruise speed in water (assuming: $\rho_{w}=1000 \mathrm{~kg} / \mathrm{m}^{3}$ ).

\section{Theoretical Model}

\subsection{Governing Equations and Evaluating Performance}

In order to evaluate the performance of a marine solid propellant water-breathing ramjet, the governing equations are presented. The general thrust equation of a jet engine is:

$$
F=\dot{m}_{e} u_{e}-\dot{m}_{w} u+\left(P_{e}-P_{a}\right)
$$

where, $F=$ thrust; $\dot{m}_{e}=$ exhaust mass flow rate; $u_{e}=$ exhaust jet velocity; $\dot{m}_{w}=$ incoming water mass flow rate; $P_{e}=$ exhaust jet static pressure. 
The specific impulse $\left(I_{s p}\right)$ of a propulsion system is an important index defined as the thrust divided by the weight flow rate of propellant consumed in order to produce the thrust, (as shown in Equation (6)). The density specific impulse $\left(\rho I_{s p}\right)$ of a propulsion system is defined as the specific impulse multiplied by the density of the propellant. For volume-limited vehicles (such as many underwater marine vehicles), the density specific impulse may be of more significant since it represents the thrust produced per volume flow rate of propellant. Thus, the specific impulse and density specific impulse can be used to compare and grade the performance of different propulsion methods. Assuming the nozzle is adapted so that the exhaust pressure is equal to ambient pressure (i.e., optimal expansion ratio for maximal thrust), the specific impulse of a marine ramjet can be calculated as following:

$$
I_{s p}=\frac{F}{\dot{m}_{p} g_{0}}=\frac{\dot{m}_{e} u_{e}-\dot{m}_{w} u}{\dot{m}_{p} g_{0}},
$$

where, $I_{s p}=$ specific impulse; $\dot{m}_{p}=$ propellant mass flow rate; and $g_{0}=$ universal gravity constant.

The exit (jet) flow rate is equal to the sum of the propellant combustion products and water flow rates, thus:

$$
\dot{m}_{e}=\dot{m}_{w}+\dot{m}_{p}
$$

Defining:

$$
\frac{w}{p}=\frac{\dot{m}_{w}}{\dot{m}_{p}}
$$

one obtains:

$$
I_{s p}=\frac{\left[1+\left(\frac{w}{p}\right)\right] u_{e}-\left(\frac{w}{p}\right) u}{g_{0}} .
$$

Assuming that the combustion chamber pressure is equal to its maximal theoretical value (i.e., the stagnation pressure) and that the ambient pressure is 1 bar (i.e., cruising at sea level), the specific impulse of a marine solid propellant water-breathing ramjet was calculated. The calculations were done according to Equation (9) with the aid of the Computer Program for Calculation of Complex Chemical Equilibrium Compositions and Applications (CEA) [16], which yields the equilibrium flow conditions and jet performance (adapted nozzle). The specific impulse and combustion chamber temperature were calculated for different propellant compositions and with different water/propellant mass ratios.

In this work, a number of propellant compositions were examined. The first composition was a common solid propellant formulation of $85 \%$ ammonium perchlorate (AP) and $15 \%$ hydroxyl terminated polybutadiene (HTPB), for which the water ingested into the motor undergoes only a phase change into steam with no chemical interaction with the burning propellant. In addition to the non-hydro-reactive AP-HTPB composition, this work deals with certain water-reactive fuels and compositions, representing the potential range of propellants and hydro-reactive propellant ingredients suitable for propelling a marine water-breathing ramjet. One hydro-reactive fuel is pure aluminum, presenting the maximum theoretical performance of aluminized propellants, since it reacts solely with the incoming water with no oxidizer stored onboard. Additional elements examined as potential fuels or propellant ingredients, were boron because of its high heat of reaction (although its practical application may be questionable), and magnesium due to its better reactivity relatively to aluminum and boron. At last, a more practical solid propellant composition, i.e., $70 \% \mathrm{Mg}$ and $30 \%$ polytetrafluoroethylene (PTFE, Teflon), was examined. The small amount of PTFE oxidizer enables initial combustion to take place without the addition of water, but being a fuel-rich propellant, the excessive fuel can react with incoming water. 


\subsection{Thrust Coefficient and Influence of Cruise Depth and Velocity on Performance}

In addition to examining the specific impulse obtained by different propellant compositions at different water to propellant mass ratios, the thrust coefficient and the influence of cruise depth and velocity on performance have been studied. It should be mentioned, that in contrast to the specific impulse which highly depends on the propellant composition and water/propellant ratio, the thrust, and therefore the thrust coefficient, weakly depends on these parameters. Thus, it was chosen in this work to present only the thrust coefficient of the more practical fuel-rich hydro-reactive propellant composition containing $70 \% \mathrm{Mg}$ and 30\% PTFE, with a constant water/propellant ratio of 3.5 (where maximal specific impulse is achieved). Yet, similar results and trends of the thrust coefficient have been observed with other compositions and at different water to propellant ratios.

Assuming the marine water-breathing ramjet is used to propel a cylindrical torpedo-shaped vehicle, the cross-section area of the body may be used as the reference area in computing the thrust and drag coefficients (Equations (10) and (11)). In addition, it was assumed that the nozzle throat diameter is $50 \%$ of the body's external diameter.

$$
C_{T}=\frac{F}{\frac{1}{2} A \rho_{w} u^{2}}
$$

where, $C_{T}=$ thrust coefficient; $A=$ reference area.

It should be mentioned that for a cylindrical torpedo-shaped vehicle with a length to diameter ratio of 15 , the drag coefficient is presumed to be smaller than 0.25 at all cruise velocities [17] and may be significantly smaller in a supercavitating vehicle cruising at a high velocity [18]. In order for the vehicle to overcome the drag force, the thrust coefficient has to be equal or larger than the drag coefficient, which is related to the same reference area:

$$
C_{D}=\frac{D}{\frac{1}{2} A \rho_{w} u^{2}}
$$

where, $C_{D}=$ drag coefficient; $D=$ drag force.

Assuming isentropic supersonic flow in the divergent section of the nozzle, the data obtained from the thermochemical code, mentioned above, enable to calculate the exit velocity and pressure as presented in Sutton and Biblatz [19], and thus the thrust (Equation (5)).

The expansion ratio is defined as the ratio between the nozzle's exit and throat cross-section areas. The results presented in this study refer to a ramjet with an expansion ratio of two cruising at a velocity in the range of 50 to $150 \mathrm{~m} / \mathrm{s}$ at a depth of 0 to $100 \mathrm{~m}$ below sea level. Atmospheric pressure ( $1 \mathrm{bar}$ ) is assumed at sea level and a pressure increase by 1 bar every $10 \mathrm{~m}$ below sea level.

\section{Results and Discussion}

\subsection{Performance of Different Propellant Compositions}

\subsubsection{Non-Hydro-Reactive Composition}

Figure 3 a presents the calculated specific impulse and density specific impulse for a solid propellant water-breathing ramjet motor with a propellant grain consisting of $85 \% \mathrm{AP}$ and $15 \%$ HTPB versus the water to propellant (w/p) mass ratio for two cruise speeds, $25 \mathrm{~m} / \mathrm{s}$ (implying chamber pressure of 4 bar) and $100 \mathrm{~m} / \mathrm{s}$ (implying chamber pressure of $50 \mathrm{bar}$ ). The values at a zero $\mathrm{w} / \mathrm{p}$ ratio represent the specific impulse of a pure rocket (no water addition). In general, the $\mathrm{w} / \mathrm{p}$ ratio is limited by the decrease of the overall chamber temperature to the water equilibrium boiling (condensation) temperature (Figure 3b). It is obvious that the addition of water increases the specific impulse (and thus the density specific impulse) substantially. However, at the low cruise speed (low chamber pressure), the specific impulse is inferior to that of a rocket motor operating at standard conditions (chamber pressure of about 69 bar). 
Nevertheless, the performance of the water-breathing ramjet at the higher chamber pressure ( $50 \mathrm{bar}$, corresponding to a cruise speed of $100 \mathrm{~m} / \mathrm{s}$ ) is noticeably higher than that of the lower pressure due to the contribution of the greater expansion in the nozzle. When cruising at $100 \mathrm{~m} / \mathrm{s}$, the specific impulse exceeds that of a standard rocket motor by as much as $30 \%$ when adding water at a w/p ratio of 2.5 .

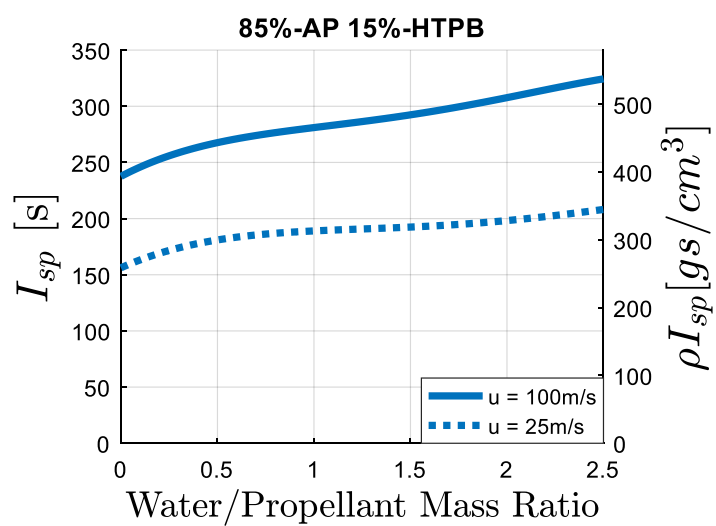

(a)

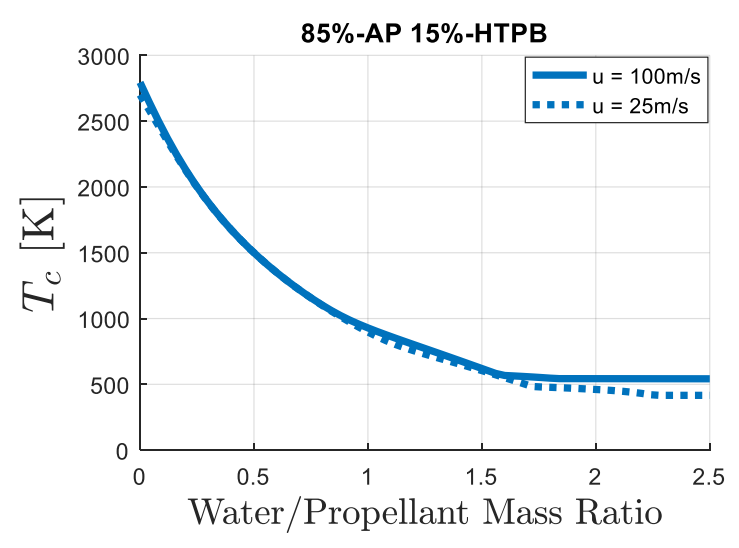

(b)

Figure 3. (a) Calculated specific impulse $-I_{s p}$, density specific impulse $-\rho I_{s p}$, and (b) combustion chamber temperature $-T_{c}$, of an underwater water-breathing ramjet using a non-hydro-reactive solid propellant $(85 \%$ ammonium perchlorate $(\mathrm{AP})+15 \%$ hydroxyl terminated polybutadiene (HTPB) $)$ vs. water/propellant mass ratio, for two different cruise velocities.

\subsubsection{Hydro-Reactive Fuels}

Figure 4a presents the theoretical specific impulse and density specific impulse for a water-breathing motor with aluminum as a fuel versus the water to propellant (fuel) mass ratio, for two cruise speeds, 25 and $100 \mathrm{~m} / \mathrm{s}$, corresponding to low (4 bar) and high (50 bar) chamber pressures, respectively. In this case, even at the low speed cruise conditions, the theoretical specific impulse of the water-breathing ramjet exceeds that of a standard rocket, the density specific impulse exceeds that of a standard rocket even more so due to the relatively high density of aluminum (compared to HTPB-AP based propellants). Figure $4 \mathrm{~b}$ presents the calculated combustion chamber temperature versus water/propellant mass ratio. It can be observed that at low w/p ratios (bellow the stoichiometric ratio) the addition of water increases the chamber temperature due to the increase in available oxidizer that enables more aluminum to react and release heat. On the other hand, at large w/p ratios, the addition of water reduces the temperature, similarly to the trend shown above in the case of a non-hydro- reactive propellant.

To be more realistic, one can take into account the fact that the reaction products of aluminum with water contain large amounts of condensed material $\left(\mathrm{Al}_{2} \mathrm{O}_{3}\right.$ or $\left.\mathrm{Al}(\mathrm{OH})_{3}\right)$ that may be retained within the motor. Hence, calculations were repeated for the case where the condensed material remains in the reaction chamber and does not exit the nozzle. Even in such case, the motor performance may be doubled and more, compared to standard solid rockets. 


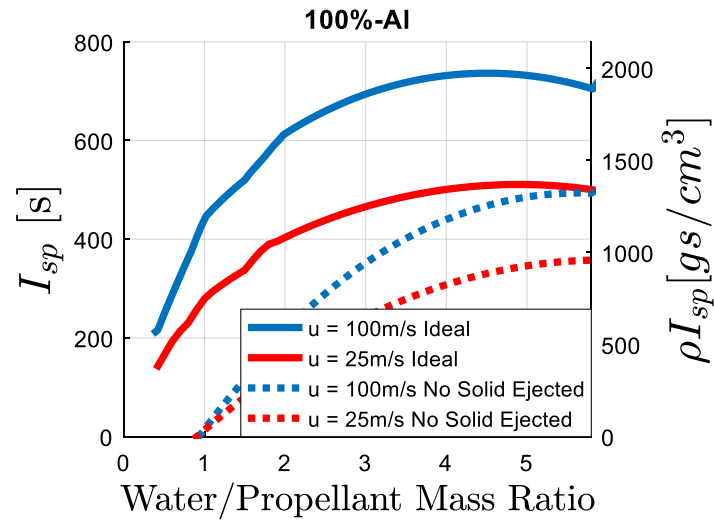

(a)

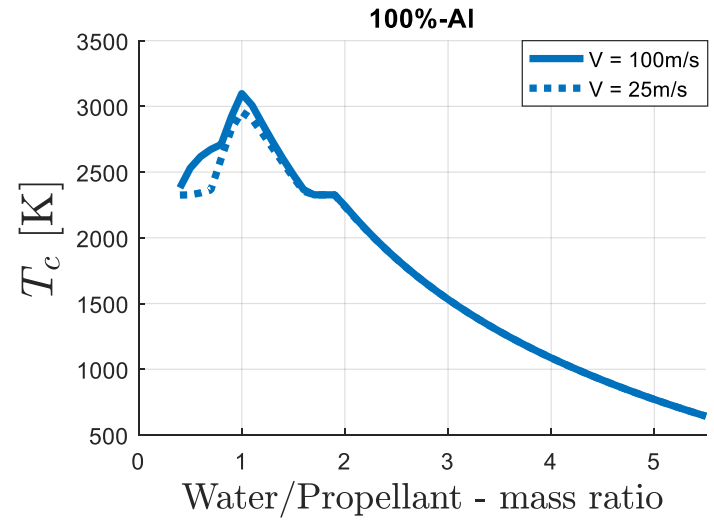

(b)

Figure 4. (a) Calculated specific impulse $-I_{s p}$, density specific impulse- $\rho I_{s p}$, and (b) combustion chamber temperature $-T_{c}$, of an underwater water-breathing ramjet using aluminum as a hydro-reactive fuel vs. water/propellant mass ratio, for two different cruise velocities.

As mentioned above, theoretically, boron as a fuel may provide the uppermost performance of a water-breathing ramjet propulsor (assuming beryllium is ruled out due to toxicity), though there is uncertainty regarding practical application. Additionally, magnesium is widely considered as a fuel for a marine ramjet due to its reactivity. Figures $5 \mathrm{a}$ and $6 \mathrm{a}$ present the theoretical specific impulse and density specific impulse of a ramjet using boron and magnesium as fuels at two cruise speeds $(100 \mathrm{~m} / \mathrm{s}$ and $25 \mathrm{~m} / \mathrm{s}$ ). It is apparent from Figure 5 a that at a cruise speed of $100 \mathrm{~m} / \mathrm{s}$ boron enables to achieve superior theoretical performance of up to four times the specific impulse achieved by an SRM, yet, even at $25 \mathrm{~m} / \mathrm{s}$ a significant specific impulse may be achievable. It should be noted, that due to the immense amount of heat released from the boron-water reaction, maximal specific impulse is achieved at a very large w/p ratio. Figure 6a reveals that the specific impulse of magnesium is inferior to that of aluminum by roughly $15 \%$ at both cruise speeds. However, due to magnesium's reactivity, which possibly implies increased combustion efficiency, magnesium is a promising fuel and can be used as an energetic propellant ingredient to improve performance of solid propellant marine ramjets. Figures $5 b$ and $6 \mathrm{~b}$ present the combustion chamber temperature of a ramjet using boron and magnesium as fuels, respectively. The trends discussed above in the case of aluminum, of an increase in temperature at a low $\mathrm{w} / \mathrm{p}$ ratio and a decrease in temperature at a large $\mathrm{w} / \mathrm{p}$ ratio, can be observed also in the cases of boron and magnesium. It should be commented, that while aluminum (Figure $4 \mathrm{~b}$ ) and magnesium (Figure $6 \mathrm{~b}$ ) present roughly an equal peak temperature of $3100 \mathrm{~K}$, the peak temperature obtained with boron (Figure $5 \mathrm{~b}$ ) is significantly lower due to the large latent heat and the relatively low temperature of evaporation of the water-boron reaction product, boron oxide. In all cases, where phase change occurs (observed as "plateaus" in the temperature figures), the phase change temperature is greater for the higher velocity due to the increased chamber pressure, which results in an elevated equilibrium vapor pressure. 


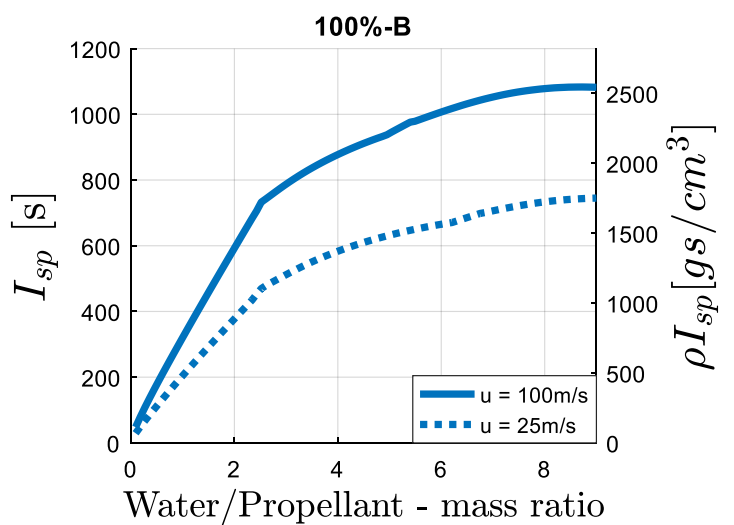

(a)

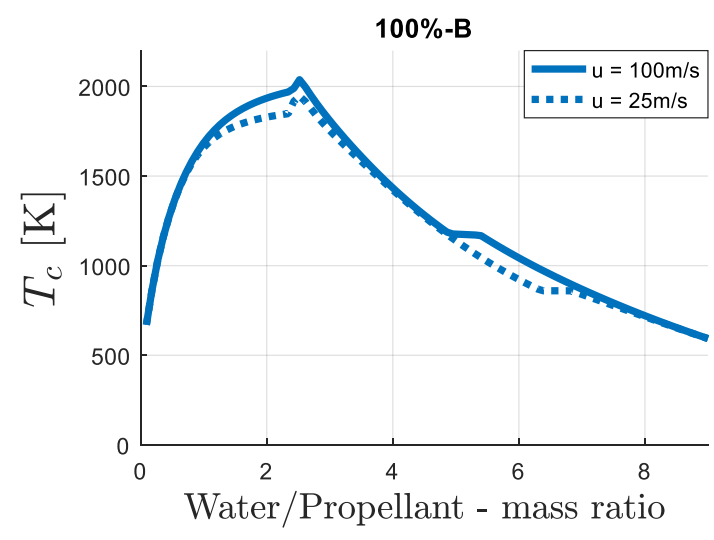

(b)

Figure 5. (a) Calculated specific impulse $-I_{s p}$, density specific impulse $-\rho I_{s p}$, and (b) combustion chamber temperature- $-T_{\mathcal{c}}$, of an underwater water-breathing ramjet using boron as a hydro-reactive fuel vs. water/propellant mass, for two different cruise velocities.

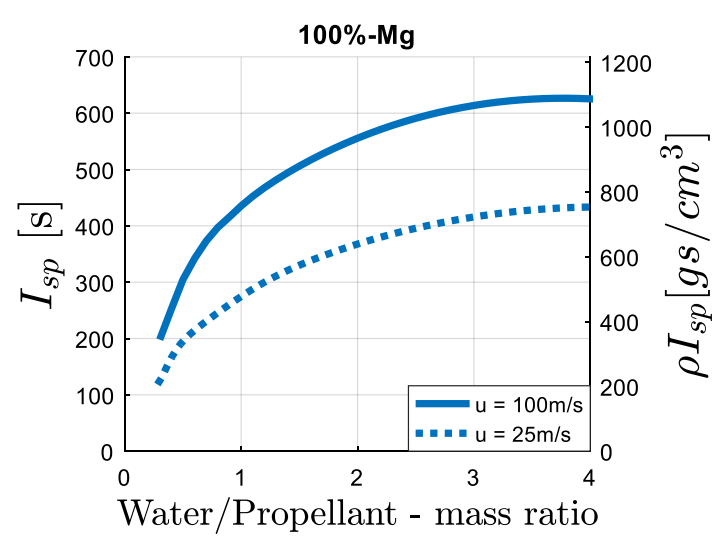

(a)

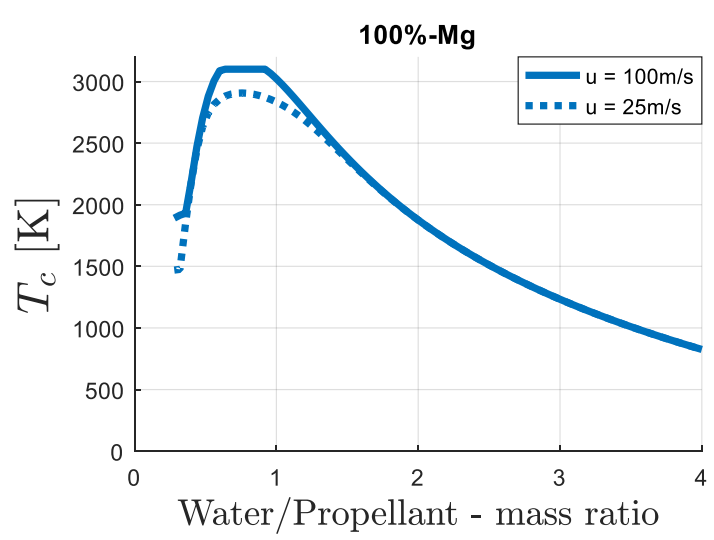

(b)

Figure 6. (a) Calculated specific impulse $-I_{s p}$, density specific impulse $-\rho I_{s p}$, and (b) combustion chamber temperature $-T_{c}$, of an underwater water-breathing ramjet using magnesium as a hydro-reactive fuel vs. water/propellant mass ratio, for two different cruise velocities.

\subsubsection{Practical Hydro-Reactive Composition}

In practice, water-reactive ingredients may be embedded within a fuel-rich propellant matrix containing a small fraction of oxidizer. Figure 7 a presents the calculated specific impulse and density specific impulse for a water-breathing ramjet motor with a propellant grain consisting of $70 \% \mathrm{Mg}$ and $30 \%$ PTFE versus the water to propellant mass ratio for two cruise speeds. This propellant composition is fuel-rich, thus also in this case maximum temperature is achieved when water is introduced in the combustion chamber as an additional oxidizer reacting with the excess magnesium, as can be seen in Figure 7b. It is apparent from Figure 7a, that the addition of a hydro-reactive fuel ingredient such as magnesium, increases significantly the performance relatively to the case of a non-hydro-reactive composition presented at the beginning. At a cruise speed of $100 \mathrm{~m} / \mathrm{s}$ it enables one to achieve a specific impulse double that achieved with a standard solid propellant rocket. 


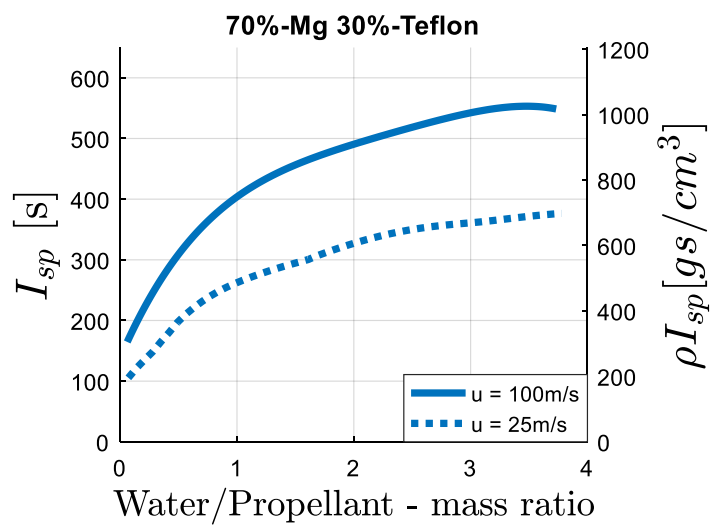

(a)

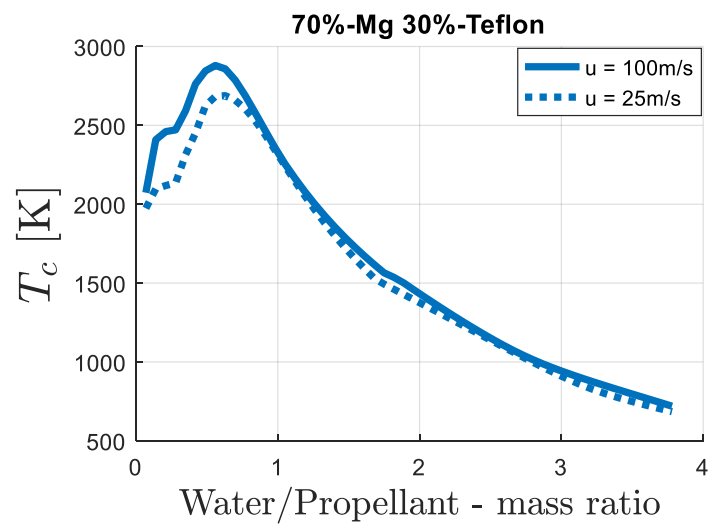

(b)

Figure 7. (a) Calculated specific impulse-Isp, density specific impulse- $\rho I_{s p}$, and (b) combustion chamber temperature $-T_{c}$, of an underwater water-breathing ramjet using a hydro-reactive fuel-rich solid propellant $(70 \% \mathrm{Mg}+30 \% \mathrm{PTFE})$ vs. water/propellant mass ratio, for two different cruise velocities.

\subsection{Thrust Coefficient and Influence of Cruise Depth and Velocity on Performance}

Figure 8 presents the thrust coefficient and the specific impulse of a marine water-breathing ramjet propelled by a solid propellant grain containing $70 \%$ magnesium and 30\% PTFE with a w/p ratio of 4 versus the cruise speed at different depths. It is apparent from Figure $8 a, b$ that with the increase in depth, the thrust coefficient and the specific impulse decrease. The reason is that the increase in ambient pressure reduces the exit nozzle performance (see Equation (5)). Yet, even at a depth of $100 \mathrm{~m}$ below sea level, the thrust coefficient is greater than the drag coefficient predicted on a torpedo-like vehicle discussed above, thus the motor can suite a broad range of velocities and depths. If necessary, the selection of a different throat diameter will enable to achieve a lower or higher thrust level (that will dictate a different propellant consumption rate).

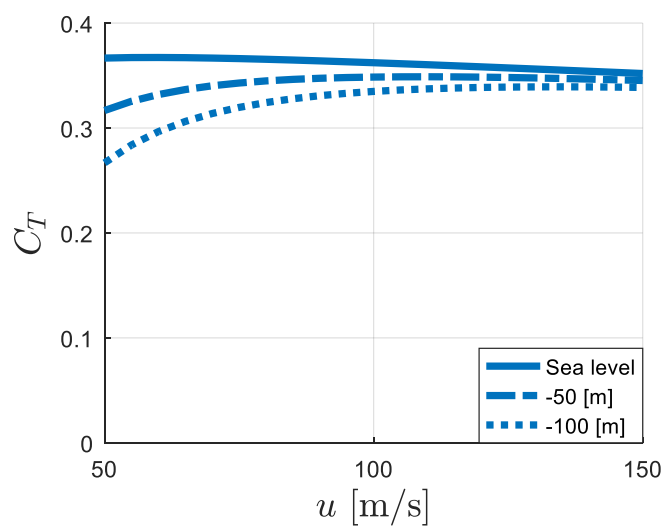

(a)

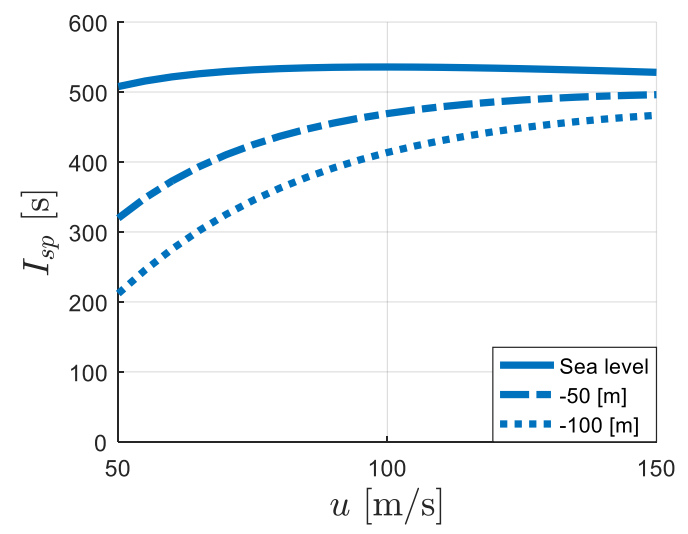

(b)

Figure 8. Calculated (a) thrust coefficient and (b) specific impulse of an underwater water-breathing ramjet with a nozzle expansion ratio of two and a throat diameter $50 \%$ of the vehicle's external diameter, using a hydro-reactive fuel-rich solid propellant $(70 \% \mathrm{Mg}+30 \% \mathrm{PTFE})$ with a water/propellant mass ratio of 3.5 vs. cruise velocity, cruising at a depths of 0,50 , and $100 \mathrm{~m}$ below sea level. 


\section{Conclusions}

The concept of a water-breathing ramjet for underwater propulsion has been evaluated theoretically based on thermochemical calculations and available practical propellants and energetic components. It is revealed that theoretically, even without chemical interaction, a solid propellant ramjet motor augmented by water entering from the surroundings through an inlet, can deliver specific impulse higher by $30 \%$ than a standard solid rocket. By introducing a fuel-rich propellant containing large amounts of a water-reactive metal such as magnesium, aluminum, or boron, the specific impulse may be doubled or more. At cruise speeds as low as $25 \mathrm{~m} / \mathrm{s}$, the performance of a water-breathing ramjet with a non-water-reactive propellant is inferior to that of a standard rocket, however, when the propellant is enriched with water-reactive ingredients, improvement in performance can be achieved even at relatively low velocities. In all cases, the specific impulse increases significantly with speed because of the increase in chamber pressure. At sea level, the thrust coefficient is almost constant at velocities between $50-150 \mathrm{~m} / \mathrm{s}$, whereas at greater depths there is a decrease in both the thrust coefficient and the specific impulse. Yet, at high velocities the thrust coefficient decreases mildly with depth, thus, the marine solid propellant water-breathing ramjet is a powerful propulsion method suitable for propelling high-speed underwater vehicles at a wide range of depths.

Author Contributions: Conceptualization, N.E.E. and A.G.; Data curation, N.E.E.; Formal analysis, N.E.E. and A.G.; Funding acquisition, A.G.; Investigation, N.E.E.; Methodology, N.E.E. and A.G.; Project administration, A.G.; Resources, A.G.; Software, N.E.E.; Supervision, A.G.; Validation, A.G.; Visualization, N.E.E.; Writing-original draft, N.E.E.; Writing-review \& editing, A.G. All authors have read and agreed to the published version of the manuscript.

Funding: This research was funded by PMRI-Peter Munk Research Institute-Technion.

Acknowledgments: The authors wish to thank David Albagli for his advice with the thermochemical calculations.

Conflicts of Interest: The authors declare no conflict of interest.

\section{References}

1. Muench, R.K.; Garrett, J.H. A Review of Two-Phase Marine Propulsion. In Proceedings of the 1972 AIAA/SNAME/USN Advanced Marine Vehicles Meeting, Annapolis, MD, USA, 17-19 July 1972.

2. Greiner, L.; Hansen, F.A. Sea-Water-Aluminum Torpedo Propulaion System. In Underwater Missile Propulsion; Greiner, L., Ed.; Compass Publications: Arlington, VA, USA, 1967; pp. 289-300.

3. Miller, T.F.; Walter, J.L.; Kiely, D.H. A Next-Generation AUV Energy System Based on Aluminum-Seawater Combustion. In Proceedings of the 2002 Workshop on Autonomous Underwater Vehicles, San Antonio, TX, USA, 20-21 June 2002; IEEE: Piscataway, NJ, USA, 2002; pp. 111-120.

4. Yang, Y.J.; He, M.G. A Theoretical Investigation of Thermodynamic Performance for a Ramjet Based on a Magnesium-Water Reaction. J. Eng. Marit. Environ. 2010, 224, 61-72. [CrossRef]

5. Huang, L.; Xia, Z.; Hu, J.; Zhu, Q. Performance Study of a Water Ramjet Engine. Sci. China Technol. Sci. 2011, 54, 877-882. [CrossRef]

6. Huang, H.T.; Zou, M.S.; Guo, X.Y.; Yang, R.J.; Li, Y.K. Analysis of the Aluminum Reaction Efficiency in a Hydro-Reactive Fuel Propellant Used for a Water Ramjet. Combust. Explos. Shock. Waves 2013, 49, 541-547. [CrossRef]

7. Hu, J.; Han, C.; Xia, Z.; Huang, L.; Huang, X. Experimental Investigation on Combustion of High-Metal Magnesium-Based Hydroreactive Fuels. J. Propuls. Power 2013, 29, 692-698. [CrossRef]

8. Ghassemi, H.; Farshi, F.H. Investigation of Interior Ballistics and Performance Analysis of Hydro-Reactive Motors. Aerosp. Sci. Technol. 2015, 41, 99-105. [CrossRef]

9. Gany, A. Innovative Concepts for High-Speed Underwater Propulsion. Int. J. Energ. Mater. Chem. Propuls. 2018, 17, 83-109. [CrossRef]

10. Rosenband, V.; Hafied, A.; Gany, A.; Timnat, Y.M. Magnesium and Boron Combustion in Hot Steam Atmosphere. Def. Sci. J. 1998, 48, 309-315. [CrossRef] 
11. Risha, G.A.; Huang, Y.; Yetter, R.A.; Yang, V.; Son, S.F.; Tappan, B.C. Combustion of Aluminum Particles with Steam and Liquid Water. In Proceedings of the 44th AIAA Aerospace Sciences Meeting and Exhibit, Reno, NV, USA, 9-12 January 2006; AIAA: Reston, VA, USA, 2006; pp. 14007-14014. [CrossRef]

12. Franzoni, F.; Milani, M.; Montorsi, L.; Golovitchev, V. Combined Hydrogen Production and Power Generation from Aluminum Combustion with Water: Analysis of the Concept. Int. J. Hydrogen Energy 2010, 35, 1548-1559. [CrossRef]

13. Rosenband, V.; Gany, A. Application of activated aluminum powder for generation of hydrogen from water. Int. J. Hydrogen Energy 2010, 35, 10898-10904. [CrossRef]

14. Elitzur, S.; Rosenband, V.; Gany, A. Study of Hydrogen Production and Storage Based on Aluminum-Water Reaction. Int. J. Hydrogen Energy 2014, 39, 6328-6334. [CrossRef]

15. Chan, S.H.; Tan, C.C.; Zhao, Y.G.; Janke, P.J. Li-SF 6 Combustion in Stored Chemical Energy Propulsion Systems. In Symposium (International) on Combustion, Proceedings of the Twenty-Third Symposium (International) on Combustion, Orleans, France, 22-27 July 1990; Elsevier: Amsterdam, The Netherlands, 1991; pp. 1139-1146.

16. Gordon, S.; McBride, B.J. Computer Program for Calculation of Complex Chemical Equilibrium Compositions and Applications; Rept. RP-1311; NASA Lewis Research Center: Cleveland, OH, USA, 1994.

17. Hoerner, S.F. Fluid-Dynamic Drag, 2nd ed.; Hoerner Fluid Dynamics: Bakersfield, CA, USA, 1965; p. 177.

18. Wolfe, W.P.; Hailey, C.E.; Oberkampf, W.L. Drag of Bodies of Revolution in Supercavitating Flow. J. Fluids Eng. 1989, 111, 300-305. [CrossRef]

19. Sutton, G.P.; Biblarz, O. Rocket Propulsion Elements, 8th ed.; John Wiley \& Sons, Inc.: Hoboken, NJ, USA, 2010; pp. 53-74.

(C) 2019 by the authors. Licensee MDPI, Basel, Switzerland. This article is an open access article distributed under the terms and conditions of the Creative Commons Attribution (CC BY) license (http://creativecommons.org/licenses/by/4.0/). 